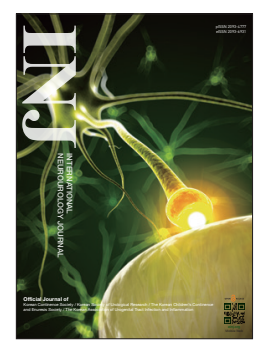

\title{
New Attempts to Overcome the Urinary Tract Disorders
}

\author{
Khae Hawn Kim (iD http://orcid.org/0000-0002-7045-8004 \\ Department of Urology, Gachon University Gil Hospital, Gachon University of Medicine and Science, Incheon, Korea \\ E-mail:kimcho99@gilhospital.com
}

In order to find new therapeutic methods and to understand their underlying mechanisms for urological disorders, International Neurourology Journal (INJ) has tried to recruit valuable articles through a special issue. In the second special issue of INJ, we have tried new attempts to overcome urinary tract disorders.

Alpha 1-adrenergic receptor ( $\alpha 1$-AR) antagonists have been used to improve lower urinary tract symptoms in an overactive bladder (OAB) [1-3]. In this issue, the add-on therapy of the a1-AR antagonists, tamsulosin and naftopidil, were tried to improve the efficacy of a1-AR antagonists on OAB symptoms. In this animal study, the enhancing effects of combination therapy of tamsulosin and naftopidil were not observed. These controversial results might be ascribed to differences in receptor affinities or animal models $[4,5]$. Continuous studies of the add-on therapy, however, might provide opportunities to find a new modality for the treatment of intractable urological disorders.

The circadian rhythm is an important clue for the maintenance of human health, and disruption of the circadian rhythm exerts adverse effects on health, including memory function [68]. In this study, the authors evaluated the circadian rhythm dependence of the effects of treadmill exercise on memory function in relation to neurogenesis. Zeitgeber is an external biological rhythm in responses to endogenous cycles which cue various actions in plants and animals [9]. Light, melatonin, and physical activity are well known zeitgebers. Light was used as the zeitgeber in this study, and the authors demonstrated that memory enhancing effect of treadmill exercise appeared more potent when exercising at daytime or evening than when exer- cising at dawn. These results suggest the possibility that treatment efficacy also depends on the circadian rhythm changes. Studies on the development of urological diseases according to the circadian rhythm changes may provide a new area for improving therapeutic effect.

The purpose of INJ is not simply to store or deliver knowledge, but to constantly explore the possibility of developing new therapies. These attempts by INJ will enable the development of new therapies for urological diseases. The Editorial Board of INJ would like to acknowledge gratitude to the authors for the valuable articles submitted to the second special issue of INJ.

- Conflict of Interest: No potential conflict of interest relevant to this article was reported.

\section{REFERENCES}

1. Kim SE, Shin MS, Kim CJ, Park JH, Chung KJ, Jung H, et al. Effects of tamsulosin on urinary bladder function and neuronal activity in the voiding centers of rats with cyclophosphamide-induced overactive bladder. Int Neurourol J 2012;16:13-22.

2. Schwinn DA, Roehrborn CG. al-adrenoceptor subtypes and lower urinary tract symptoms. Int J Urol 2008;15:193-9.

3. Athanasopoulos A, Gyftopoulos K, Giannitsas K, Fisfis J, Perimenis P, Barbalias G. Combination treatment with an $\alpha$-blocker plus an anticholinergic for bladder outlet obstruction: a prospective, randomized, controlled study. J Urol 2003;169:2253-6.

4. Kim SE, Shin MS, Kim CJ, Park JH, Chung KJ, Jung H, et al. Effects of tamsulosin on urinary bladder function and neuronal activity in 
the voiding centers of rats with cyclophosphamide-induced overactive bladder. Int Neurourol J 2012;16:13-22.

5. Nishino Y, Masue T, Miwa K, Takahashi Y, Ishihara S, Deguchi T. Comparison of two al-adrenoceptor antagonists, naftopidil and tamsulosin hydrochloride, in the treatment of lower urinary tract symptoms with benign prostatic hyperplasia: a randomized crossover study. BJU Int 2006;97:747-51.

6. Chaudhury D, Wang LM, Colwell CS. Circadian regulation of hippocampal long-term potentiation. J Biol Rhythms 2005;20:225-36.

7. Sgoifo A, Buwalda B, Roos M, Costoli T, Merati G, Meerlo P. Ef- fects of sleep deprivation on cardiac autonomic and pituitary-adrenocortical stress reactivity in rats. Psychoneuroendocrinology 2006; 31:197-208.

8. Wang G, Grone B, Colas D, Appelbaum L, Mourrain P. Synaptic plasticity in sleep: learning, homeostasis and disease. Trends Neurosci 2011;34:452-63.

9. Kim KT, Kim CH, Kwon B, Han DH, Yoon SJ, Cho S, et al. Do rotational shifts affect micturition patterns in real practice? A pilot study in healthy, young female nurses. Int Neurourol J 2014;18:20612. 